\title{
Implementation of Teledermatology: Theory and Practice
}

\author{
Sara B. Peracca ${ }^{1} \cdot$ George L. Jackson ${ }^{2,3} \cdot$ Martin A. Weinstock ${ }^{4,5} \cdot$ Dennis H. Oh ${ }^{1,6}$
}

Published online: 2 May 2019

(C) The Author(s) 2019

\begin{abstract}
Purpose of Review Multiple factors influence the success and failure of teledermatology programs. We evaluate the current teledermatology literature using the Reach, Effectiveness, Adoption, Implementation, and Maintenance (RE-AIM) framework developed for implementation research. We introduce this framework to encourage a thorough examination of teledermatology's implementation including its sustainability. In this way, programs can better realize teledermatology's promise for enhancing patients' access to expert dermatologic care in real-world healthcare settings.

Recent Findings While teledermatology continues to expand throughout the world, barriers continue to exist. Many evaluations of teledermatology focus on the effectiveness of the programs, without examining other factors that underlie success. The use of implementation science enables researchers to better assess different factors influencing a program's success or failure.

Summary Implementation science offers theories, frameworks, and methodologies to study and improve teledermatology's impact.
\end{abstract}

Keywords Teledermatology $\cdot$ Implementation $\cdot$ RE-AIM $\cdot$ Reach $\cdot$ Adoption $\cdot$ Effectiveness $\cdot$ Maintenance

$\begin{array}{ll}\text { Abbreviations } \\ \text { ACGME } & \begin{array}{l}\text { Accreditation Council for Graduate } \\ \text { Medical Education }\end{array} \\ \text { ATA } & \text { American Telemedicine Association } \\ \text { AAD } & \text { American Academy of Dermatology } \\ \text { OTIE } & \begin{array}{l}\text { Organizational Theory of } \\ \text { Implementation Effectiveness }\end{array}\end{array}$

This article is part of the Topical Collection on Teledermatology

Sara B. Peracca

sara.peracca@va.gov

1 Dermatology Research Unit (190), San Francisco Veterans Affairs Health Care System, 4150 Clement Street, San Francisco, CA 94121, USA

2 Center of Innovation to Accelerate Discovery and Practice Transformation (ADAPT), Durham Veterans Affairs Health Care System, Durham, NC, USA

3 Deparment of Population Health Sciences and Division of General Internal Medicine, Duke University, Durham, NC, USA

4 Providence Veterans Affairs Medical Center, Providence, RI, USA

5 Department of Dermatology, Brown University, Providence, RI, USA

6 Department of Dermatology, University of California at San Francisco, San Francisco, CA, USA

$\begin{array}{ll}\text { PCPs } & \text { Primary Care Providers } \\ \text { RE-AIM } & \begin{array}{l}\text { Reach, Effectiveness, Adoption, } \\ \text { Implementation, Maintenance }\end{array} \\ \text { SIC } & \text { Stages of Implementation Completion } \\ \text { TAM } & \text { Technology Acceptance Model } \\ \text { US } & \text { United States of America } \\ \text { VA } & \text { Department of Veterans Affairs }\end{array}$

\section{Introduction}

With a limited dermatology workforce, teledermatology has been a growing area of telemedicine since the 1990s. No longer primarily in academia, teledermatology has penetrated all practice settings, with particular prominence in the United States (US) within the Department of Veterans Affairs (VA) and the military [1]. Teledermatology enables the transmission of a patient's clinical history and skin images to a dermatologist, who then provides a diagnosis and management plan. The teledermatology modalities are (1) store-and-forward, the most common modality in the US, which uses still photographic images that are typically evaluated by a dermatologist at a separate time and location from the patient's visit [2••] and (2) live interactive video conferencing, which enables realtime evaluation when the patient and dermatologist are in separate locations. 
Research in teledermatology has validated its diagnostic accuracy and management effectiveness leading to clinical outcomes that are at least comparable to usual, in-person dermatologic care [3••]. However, in spite of teledermatology's clear benefits for broadly increasing access to dermatology care, its growth has not been uniform and discontinuation of programs frequently occurs $[2 \bullet \bullet, 4]$. While multiple factors contribute to the success of teledermatology, the high rate of program failures illustrates the need for systematic research of teledermatology's implementation and sustainability to understand how to fully realize teledermatology's promise for enhancing patients' access to expert dermatologic care in real-world healthcare settings. In this review, we discuss some approaches for assessing implementation and sustainability, and use one framework to review the recent teledermatology literature.

\section{Implementation Research}

Few studies fully assess all aspects of teledermatology programs to understand the process of integrating teledermatology into a healthcare system. Integration requires multiple steps to engage the range of stakeholders, including leadership, staff members, and populations served. Stakeholders must see value in teledermatology, have access to and know how to use relevant tools and procedures, and have confidence in their ability to participate in teledermatology. Providers must fit teledermatology into their everyday workflow and be sufficiently reimbursed for their efforts. Additional considerations include the regulatory environment and legal issues that may impact the growth and continuity of teledermatology programs.

Implementation science offers frameworks for understanding the strategies used to integrate teledermatology within healthcare systems; it can also be used to evaluate the integration itself. It provides methodologies and tools to measure whether and why an intervention is effective, providing information about the entire process of planning, deployment, adoption, maturation, and sustainment [5-7, 8•]. Assessment can include the identification of barriers and facilitators to practicing teledermatology, as well as an examination of the setting in which it takes place. Implementation science can facilitate greater understanding of how to successfully integrate and sustain teledermatology in healthcare systems, and why teledermatology programs fail [9].

One useful paradigm for considering interventions in healthcare organizations is the Organizational Theory of Implementation Effectiveness (OTIE), adapted by Weiner and colleagues from work by Klein and Sorra [10-15]. OTIE posits that effective implementation, along with resulting intervention effectiveness and sustainability, is a function of five factors (Fig. 1): (1) healthcare facilities' organizational readiness for change, which is a combination of a commitment to and efficacy of implementing teledermatology; (2) quality of the organization's implementation policies and practices; (3) climate for implementation; (4) extent to which intended users of the intervention (e.g., providers, patients) perceive that it fosters the fulfillment of their values; and (5) extent to which the innovation fits with task requirements. The organizational benefits of improved patient care, for example, depend on how well and how consistently intended users adopt the innovation. The sustainability of the intervention, which should also be considered, depends on innovation effectiveness, continued availability of resources, and ongoing investment of resources in implementation practices (e.g., training, communication systems).

Many implementation frameworks have been developed for planning and research, some with underlying theories (see for example Tabak 2012 who reviewed 62 dissemination and implementation science models) [16]. In addition to the OTIE, a few examples that are particularly relevant for the healthcare sector and that assess factors at multiple operational levels include (1) Reach, Effectiveness, Adoption, Implementation, and Maintenance (RE-AIM, discussed below) [17-19]; (2) Consolidated Framework for Implementation Research [20]; (3) Theory of Diffusion of Innovations [21]; (4) Precede-Proceed (derived from health behavior theory) [22]; and (5) Ottawa Model of Research Use (used broadly in health including dermatology) [23].

We use the Glasgow RE-AIM framework to organize the recent teledermatology literature into various implementation outcomes [17-19] (see Table 1). As a framework for understanding the implementation of a particular intervention, REAIM is valuable for several reasons. First, the framework is roughly aligned with the factors set out in the OTIE and thus facilitates connections between theory and practice. Second, it is readily translated into operational stages, recognizing the importance of examining both pre-implementation and sustainability measures to ensure that an effective teledermatology program is not only started but that changes are made to ensure it lasts. Third, this framework examines factors at the individual, organizational, and community level, and finally, the model is somewhat flexible, whereby the specific definitions of each dimension within the framework are broadly defined and thus can be modified to fit the particular aspects of teledermatology. RE-AIM has been used widely since its 1999 introduction [17-19], though a 2013 review of 71 studies, which had used the RE-AIM framework, did not identify any teledermatology or telemedicine programs [24]. Since then, two evaluations have used the framework to evaluate telemedicine, one comparing programs at 4 diverse healthcare systems in the US and Canada and the other comparing a program in two different areas of Ontario, Canada [25, 26]. More recently, RE-AIM has been used by the VA as the standard framework to evaluate its rural health programs, including an enterprise-wide initiative in teledermatology [27].

In this review, we summarize the teledermatology literature published during 2015-2018, focusing on original research 
Fig. 1 Components of the Organizational Theory of Implementation Effectiveness (OTIE). Adapted from Weiner et al. [12]

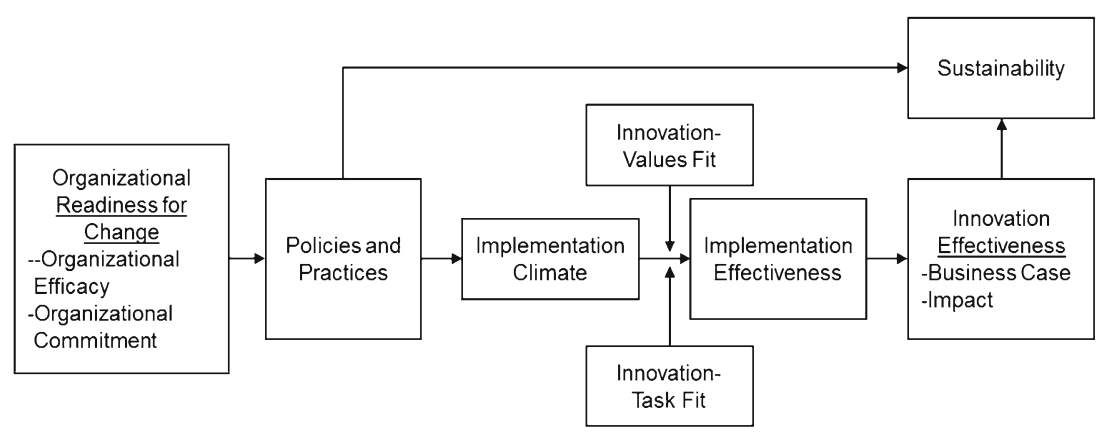

rather than reviews or commentaries, and categorize them within the RE-AIM framework according to its five factors (Fig. 2). We conducted a literature search using the PubMed database, searching with broad key words such as Teledermatology, Implementation, RE-AIM, and e-consult. For consideration, manuscripts were required to discuss at least one of the five RE-AIM dimensions, though specific reference to the RE-AIM framework was not required. Since a few studies discuss more than one factor, we sometimes discuss different findings from the same study in different sections of the RE-AIM framework. Rather than an exhaustive review for each area, we focus attention on the published work most relevant for implementation, emphasizing the importance of an implementation strategy when beginning a teledermatology program and the need to identify areas for further implementation research in the teledermatology field.

\section{Reach}

Reach refers to the extent to which stakeholders are affected. In the context of teledermatology, it can be the degree to which individuals are impacted, such as the number of patients who receive care via teledermatology or the number of instances of care. However, within a healthcare organization, reach can also include surrogate measures such as the number of participating clinics, the geographic area served, the number of providers trained, and other markers of teledermatology activity. Teledermatology programs often have ready access to these types of data and thus studies of reach in teledermatology are common.

There are many studies that have reported teledermatology activity worldwide. Mass teledermatology screening events, as a means of increasing reach, have been studied in France, for example, particularly targeting agricultural workers who would not have otherwise received dermatologic care [28]. In Spain, 43,677 patients received teledermatology services between 2004 and 2014 [29]. In Queensland, Australia, 318 teledermatology referrals were noted in 2014, nearly doubling since 2012 [30]; and in the Netherlands, which has a more active program, 130,531 teledermatology consults were conducted between 2006 and 2015 [31]. In low- and moderate-income countries, particularly in remote areas, teledermatology has increased access, broadly defined as numbers of teledermatology encounters, as shown by studies in Afghanistan [32], 12 sub-Saharan African countries [33], and Mali [34]. Secure messaging as a vehicle for increasing teledermatology reach has been reported in Botswana [35] and Argentina [36], while a common commercial file sharing resource has been used in Egypt [37]. In Brazil, teledermatology has expanded to cover the entire state of Catarina with 83,100 completed consults from January 2014 to June 2018 [38]. Some of these studies evaluated pilot programs and thus it will be important for follow-up studies to re-examine the reach of these programs as one measure of their success as they mature.

In the US, a $48 \%$ increase in the overall number of nongovernmental teledermatology programs occurred over 5 years since 2011 along with an increase in overall patient volume (with a range from 20 to 20,000 consults) [2••]. The VA has an extensive teledermatology program with 62 participating facilities and $>101,000$ store-and-forward teledermatology encounters in 2016 alone [2••]. Illustrating the recent growth of teledermatology in VA, $14 \%$ of all teledermatology visits since 2002 occurred in the first half of the fiscal year 2014, with 234,928 encounters during the entire study period [39•]. During a 6-month period in 2012, one VA teledermatology program reported a $40 \%$ increase in requests for dermatologic services overall after store-and-forward teledermatology was introduced [40]. A rapid increase in access to dermatology was similarly observed amongst individuals in the US using Medicaid; following the introduction of teledermatology, the dermatology visit rate increased from 0.50 to 1.24 dermatology visits per 1000 enrollees [41].

Teledermatology was largely introduced for rural Veterans in the VA; however, urban Veterans have now constituted the majority of patients served since 2012 [39"]. Teledermatology has also been introduced to increase access to dermatologic care amongst medically underserved urban populations in the US [42] and in resource-poor outpatient settings, with one study finding that at least $61 \%$ of referred patients would not have received dermatologic care without teledermatology [43].

While studies typically identify the number of participants, they do not often examine the reach of a program over time. To more fully understand who is benefiting from a program, longitudinal data regarding both patients served and staff 
Table 1 Summary and example results for each of the RE-AIM components

\begin{tabular}{|c|c|c|}
\hline RE-AIM domain & Domain description & Possible outcomes \\
\hline Reach & Degree to which populations are impacted & $\begin{array}{l}\text { What is extent of teledermatology program(s)? } \\
\text {-\# of teledermatology patients by various characteristics (e.g., rural) } \\
\text { - \% of dermatology encounters } \\
\text {-\# completed teledermatology consults } \\
\text {-\# of teledermatology programs } \\
\text {-\# of providers trained }\end{array}$ \\
\hline Effectiveness & $\begin{array}{l}\text { Ability of program to change patient-centric } \\
\text { outcomes with quality of care }\end{array}$ & $\begin{array}{l}\text { Does program facilitate access to equal quality dermatology services? } \\
\text { - Improvements in patient health outcomes } \\
\text { - Diagnostic and management concordance } \\
\text { - Consult/appointment completion times/wait times and no-shows } \\
\text { - Dermatologic skill level of PCPs } \\
\text { - Quality of life } \\
\text { - Costs, e.g., staff, technology, visit, pharmacy, travel, loss of productivity } \\
\text { - Patient/provider satisfaction }\end{array}$ \\
\hline Adoption & $\begin{array}{l}\text { Degree to which program is used by } \\
\text { end-users }\end{array}$ & $\begin{array}{l}\text { How is program being implemented? } \\
\text { - Examining Stages of Implementation Completion } \\
\text { - Understanding link between institutional readiness for change and adoption } \\
\text { - \% PCPs and dermatologists using teledermatology } \\
\text { - Extent to which clinics are implementing a program by understanding } \\
\text { administrative landscape, staffing and training needs }\end{array}$ \\
\hline Implementation & $\begin{array}{l}\text { Degree to which program is implemented as } \\
\text { planned }\end{array}$ & $\begin{array}{l}\text { Are facilities in a position to implement teledermatology? } \\
\text { - Determination of detailed barriers to and facilitators of implementation } \\
\text { - Understanding link between individual and institutional readiness for } \\
\text { change and successful implementation } \\
\text { - Whether the teledermatology process is aligned with guidelines (also } \\
\text { called intervention fidelity) } \\
\text { - Assess different stakeholder perspectives }\end{array}$ \\
\hline Maintenance & Can program be sustained over time? & $\begin{array}{l}\text { Implementation maintenance outcome } \\
\text { - Examination of program implementation over time including assessment of } \\
\text { long-term funding, collaboration and commitment between and fr } \\
\text { leadership, staff, and the community } \\
\text { - Assessment of program responsivity such as addressing workflow and } \\
\text { access to technology } \\
\text { - Assess program results (e.g., change in number of teledermatology } \\
\text { consults/encounters over time) } \\
\text { - Identification of training programs to ensure staff involvement and } \\
\text { integration, and to address staff attrition }\end{array}$ \\
\hline
\end{tabular}

trained or participating in teledermatology programs will better facilitate improvements to programs and allow for a better understanding of where resources should be focused.

\section{Effectiveness}

Because a common motivation for implementing teledermatology is to improve patient access to expert dermatologic care, access has components of both reach and effectiveness and it is often difficult to separate these two types of outcomes. While effectiveness includes patient and provider satisfaction [44-46], for our purposes, effectiveness is the ability of an intervention to change patient-centric outcomes such as reductions in distance traveled by patients, consult completion times, and improvements in actual and intermediate surrogate measures of patient health outcomes. We also discuss cost-effectiveness, which can affect not only patients but also healthcare organizations and payors.

Numerous studies have documented the diagnostic and management concordance of store-and-forward teledermatology with in-person consultations; recent studies have continued to confirm these conclusions [47-49]. Studies have also found high concordance with in-person care with the use of mobile technology in teledermatology [50], particularly for skin cancer screening, though studies have found reduced image quality associated with mobile device cameras compared with conventional digital cameras [49].

Teledermatology has been beneficial for triage by decreasing wait times [45], no-shows, and face to face referrals for the general population [3••] and amongst medically underserved populations [51•]. In the VA, teledermatology decreased wait times from 60.6 to 10.3 days in one program, reduced noshows for in-person dermatology clinics in another, and 
Fig. 2 Dimensions of the Reach, Effectiveness, Adoption, Implementation, Maintenance (RE-AIM) Framework

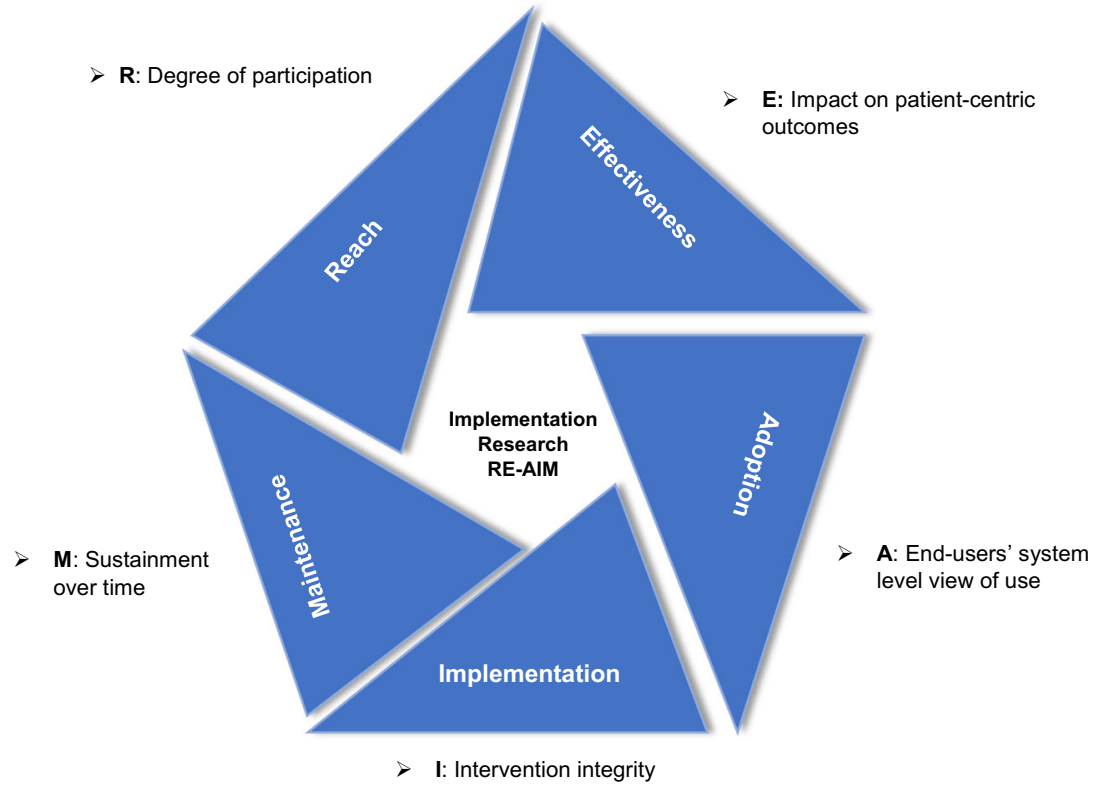

increased efficiency if used as a means to triage patients directly to Mohs Surgery [40, 52, 53].

Two under-examined effectiveness outcomes of teledermatology are the dermatologic skill level of primary care providers (PCPs) and quality of life. An increase in PCP skill level as a result of teledermatology has been reported, potentially leading to reductions in misdiagnosis by PCPs and faster treatment for patients locally, and is an area for active investigation in the future [54•]. Positive quality of life outcomes have also been associated with teledermatology, though additional research is needed to examine patients who solely receive teledermatology [55].

While not typically considered a patient-centric outcome, cost is an important measure of teledermatology's effectiveness. When compared with in-person visits, store-and-forward teledermatology has largely been found to reduce costs for healthcare organizations, individuals, and society, regardless if the consult originates from a provider $[56,57]$ or a patient $[45]$. The definition of cost used in these analyses varies, defined, for example, as staff and technology costs [57], costs of the visit [58], pharmacy costs [45], or more thoroughly as visit, pharmacy, travel, hospitalization, and loss of productivity costs [59•]. This last study, using a more comprehensive list of incurred costs, also used the time trade-off method to assess the utility and found no benefit to teledermatology. They also found no benefit if considering VA costs alone but found a benefit when considering the full societal costs [59•]. Lastly, the use of smart phones has been found to save PCPs time when compared with the use of a conventional digital camera, which can be equated to saving money for the provider or healthcare system [50].

Direct-to-patient care is a growing area of teledermatology. Studies have found high concordance of direct-to-patient care with in-person care [60]. Research on the accuracy of mobile direct-to-patient teledermatology algorithms that enable the user to self-diagnose has noted the potential for inadequate diagnoses [61, 62•], though it was found to be accurate in diagnosing and treating psoriasis [63].

While much research has focused on various measures of effectiveness, a continuing need exists for further high-quality research assessing actual clinical outcomes of patients managed by both store-and-forward and live interactive teledermatology.

\section{Adoption}

Adoption refers broadly to the degree to which interventions such as teledermatology are used by end-users, including a consideration of the characteristics of the setting. In this section, we discuss the extent to which models developed for national and small-scale programs address aspects of the three implementation phases: pre-implementation, implementation, and sustainability to understand the participation and representativeness of users. The Stages of Implementation Completion (SIC), which was developed to track time to achievement, facilitates this examination because it divides these phases into eight stages: pre-implementation (1-stakeholder engagement; 2-feasibility consideration; 3readiness planning), implementation (4-staff trained, 5monitoring set up, 6-activities started, 7-monitoring feedback incorporated), and sustainability (8-competency achieved) [64, 65].

In South Africa, a model to scale a teledermatology program nationally specified a multitude of activities to address 
all three implementation phases [66]. We highlight their preimplementation phase, which identified the need for communication strategies and understanding the national and provincial government operational objectives and budget thereby recognizing the need to engage stakeholders, understand feasibility, and identify South Africa's readiness. A partnered project between the US and Belize entities similarly identified the importance of communication by establishing a system to share information, utilizing the expertise of each partner [67•]; thereby developing the readiness of partners.

Conducting a local assessment is a valuable way to engage stakeholders in the pre-implementation phase to understand the needs and feasibility of a program [68]. The Belize partnered program gained support as a result of their assessment because it was found to be mutually beneficial [67•]. An assessment also provides information about the current system, including costs and the availability of resources. The involvement of the community and local partners recognizes the value of collaboration, which is critical for ensuring a successful sustainable program, particularly when programs involve high- and low/moderate-income countries [69].

The importance of understanding the administrative landscape, such as the creation of guidelines that outline agreed upon protocols and standards for initial and follow-up procedures, is not prescriptively outlined in RE-AIM, since it is broad in scope [17-19]. However, the lack of standards and guidelines is a common barrier to program adoption (see also the "Implementation Research" section). It is notable that both the American Telemedicine Association (ATA) [70] and the American Academy of Dermatology (AAD) both published teledermatology practice standards and guidelines in 2016. While both guidelines share common elements, the AAD guidelines emphasize preservation of the choice of conventional inperson care, encourage continuity of the patient-physician relationship, and are more proscriptive concerning direct-to-patient teledermatology [71], whereas the ATA guidelines focus on promoting successful elements of all teledermatology practices [70].

Related to guidelines, there is a need to understand the legal and regulatory setting. For example, South Africa's National Health Normative Standards for Interoperability and eHealth Governance were considered in implementing its teledermatology program [66]. Similarly, preconditions needed to start a teledermatology program, include the importance of understanding legal/licensure and ethical issues, as governments (e.g., countries, states, provinces) and organizational subunits may differ in how they regulate interactions when patient and consultants are located in different jurisdictions [31]. For example, in the US, providing teledermatology across state lines often requires additional licensure requirements [72], increasing costs of teledermatology for these organizations and/or private clinics. VA recently addressed this issue by developing regulations and a new law to allow VA healthcare providers to practice telehealth across state boundaries [73, 74].
During the implementation phase, one of the key stages is to consider staffing and training concerns. At this time, one may find value in using the technology acceptance model (TAM) $[75,76]$ to ascertain which factors drive the provider's intention to participate fully in teledermatology and to encourage high participation rates.

An adoption model developed as part of the Momentum project to facilitate a standardized national system for telemedicine in Europe identified 18 critical factors that incorporate aspects of the RE-AIM framework [77]. By including a toolkit for staff at various levels to assess institutional performance, including cultural readiness, the model recognizes the importance of assessing both an individual's and an organization's readiness to change. Both are important determinants of effecting organizational change according to the theory of organizational readiness for change [78].

In sum, while theoretical models for adoption exist that can be adapted to teledermatology implementation, much additional empirical data to test these models is still needed. Future programs should consider including a rigorous monitoring component to enable future research to better ascertain adherence to protocols and standards and to identify improvements.

\section{Implementation}

Implementation refers to the ability to operate programs as planned. When monitoring a program during its implementation phase, one gains an understanding of how it is being delivered by identifying barriers and facilitators. For example, identifying the lack of an implementation strategy as a barrier could lead to a more successful teledermatology program. Without clear goals and processes, the implementation phase is likely to fail.

It is also important that an implementation strategy include a communication strategy, which amongst other things facilitates an understanding of individual and institutional readiness for change. A lack of communication and coordination between referring providers and dermatologists has emerged as an implementation barrier for teledermatology programs [27, $62 \cdot, 79,80]$. In a chart review of 187 e-consults at the Mayo Clinic in the US, $10 \%$ of recommendations were not completed. Though none of these consults were for dermatology [81], the finding illustrates a very basic communication problem in the teledermatology process itself. Communication facilitates an understanding of the perspectives of patients, healthcare professionals, policy makers, insurers, and the organizations themselves. For example, an examination of eHealth in primary health care serving a variety of specialities, including dermatology, found that understanding the perspectives of each of these groups, enabled eHealth to be effective and continue to thrive [82]. The importance of understanding the providers' perspectives was also shown in a study of 
emergency department providers, where only $12 \%$ of providers stated that teledermatology can effectively replace inperson consultations [83], suggesting the importance of early education during implementation.

Concerns regarding privacy and security exist regarding how histories and images are sent, and if programs obtain patient consent $[79,84,85]$. These concerns are particularly relevant with the increased use of mobile phones [86] and direct-to-patient care [87]. Networking platforms for consultative purposes in particular such as Telederm.org, Sermo, and Facebook raise concerns regarding patient privacy, confidentiality, and the security of data [68].

Although a variety of different business models exist for reimbursement, resources are still not always secure and act as a barrier to expansion and sustainment. In the US, while some states have passed laws to mandate that reimbursement for inperson care is the same as telemedicine, procedures are more highly reimbursed by insurance and thus the fee for service model actually has a disincentive to adopt teledermatology [88].

Pharmacy restrictions act as an additional barrier in underserved populations as evidenced in an urban area in the US [42] and in Belize [67•], as does limited access to labs and an underdeveloped infrastructure, which is often the experience in remote areas [89]. Another barrier, especially for remote areas, is inaccessibility to the Internet and poor connection quality, since mobile devices are being used more readily as a tool to provide access in these areas throughout the world [34, 68].

The creation of a virtual office as a new practice setting is seen as a new facilitator for growth in direct-to-patient care [2••] but this type of care can also experience operational inefficiencies. For example, in commercial systems, often there is little to no integration with the patient's official medical record $[62 \cdot, 90]$. Addressing this inefficiency not only saved dermatologists time but also reduced the time to diagnosis and treatment from 23 days to $16 \mathrm{~h}$ in one program [91].

Finally, inadequate follow-up is a barrier to implementation of quality teledermatology [42]. A teledermatology program in 12 countries in sub-Saharan Africa with purposefully limited guidelines and simple record keeping requirements led to wide variability in clinical histories and an inability to track returning patients [33]. In the US, a study of the teledermatology program at the Atlanta VA found that providers only followed up $40.8 \%$ of recommendations for reassuring patients and $24.6 \%$ of recommendations for prescribing medications [92].

In sum, monitoring programs are essential to fully optimize teledermatology implementation and understand its value and usage. Monitoring can identify key barriers and facilitators, which can vary depending on the program, providing feedback so that programs can adjust to new challenges and thereby ensure sustainment [67•]. An area for future research is to understand in greater detail strategies to implement teledermatology and the role and costs of various stages as identified in SIC in expanding or limiting teledermatology.

\section{Maintenance}

Maintenance refers to sustainment of teledermatology programs over time. Funding is a critical limiting factor for teledermatology programs $[30,42,93]$. Short-term grant funding rarely sustains programs but diverse sources of funding, including fee for service, generally alleviate funding difficulties to maintain programs. Nevertheless, effective strategies for long-term funding still face challenges: for example, the national program in the Netherlands reported challenges with securing reimbursement [31]. Lack of funding impacts small- and large-scale programs alike.

In addition to the importance of securing funding, a more recent assessment of telemedicine in the Netherlands highlighted a few additional key components to sustaining programs such as the importance of program responsivity, which included creating efficient workflows and supporting providers to manage the program by ensuring adequate staffing and the availability of appropriate technology. It also stressed the importance of support from leadership, specifically government support for innovation [82].

Training of primary care providers is an important component to sustaining successful programs as evidenced in Belize [67-], in Australia with remote practitioners [94], and within the Atlanta VA with PCPs at community-based outpatient clinics [92]. Innovative programs using smartphones have served to both train local providers as well as provide effective healthcare delivery, using a medical student proxy in Uganda and Guatemala [95], and in a remote area of Columbia, using an app [96].

By incorporating teledermatology training into residency programs, not only does access to dermatology increase but also residents' knowledge acquisition increases. In the US, VA is prominently represented as a teledermatology training venue for residency programs. At one VA facility, resident involvement in teledermatology led to an increase in knowledge of four of the core Accreditation Council for Graduate Medical Education (ACGME) competences: patient care, medical knowledge, practice-based learning and improvement, and systems-based practice [97]. Dermatology residents can also gain experience in diagnosis and management of skin diseases in unfamiliar resource-limited settings through a virtual grand rounds curriculum thereby introducing socioeconomic, cultural, and ethical considerations related to skin health [98]. However, impediments to incorporating teledermatology into dermatology residency programs exist, including reimbursement issues, an inability to adequately evaluate lesions, and insufficient time [99].

In summary, maintenance is a critical component of teledermatology implementation but is relatively underrepresented in the literature. This may change in the future 
as teledermatology continues to mature. It will be important to learn about both successful and discontinued programs, including the economic, organizational factors associated with each (see Mancini \& Marek for a tool to assess sustainability [100]). Studies on effective training methods are equally important to ensure the next generation of dermatologists practices teledermatology responsibly and effectively.

\section{Conclusion}

Many studies in the existing literature report on one dimension of the RE-AIM framework. While each dimension is important, the dimensions are interdependent. Future investigations should systematically examine as many of the different dimensions included in the RE-AIM framework as possible to ensure a comprehensive understanding of teledermatology implementation. Additional studies focused on documenting the implementation and, equally important, the sustainment of teledermatology programs are needed to ensure that the benefits of teledermatology are fully realized. Table 1 provides a summary of the RE-AIM properties, their description and possible outcomes for teledermatology as discussed in this article.

Acknowledgments We thank Ms. Olevie Lachica for expert assistance in preparing the manuscript. Supported by the Department of Veterans Affairs Health Services Research and Development Service, Award 1I01 HX002450-01 (D.H.O. and M.A.W.), and the Durham Center of Innovation to Accelerate Discovery and Practice Transformation (ADAPT) CIN 13-410 (G.L.J.).

Funding Information George L. Jackson received grants from the United States Department of Veterans Affairs, Health Services Research \& Development Service, and from the Bristol-Myers Squibb Foundation.

\section{Compliance with Ethical Standards}

Conflict of Interest Sara B. Peracca, Martin A. Weinstock, and Dennis H. Oh declare no conflict of interest.

Human and Animal Rights and Informed Consent This article does not contain any studies with human or animal subjects performed by any of the authors.

Disclaimer The views expressed in this paper are those of the authors and do not reflect the position or policy of the Department of Veterans Affairs or the United States government.

Open Access This article is distributed under the terms of the Creative Commons Attribution 4.0 International License (http:// creativecommons.org/licenses/by/4.0/), which permits unrestricted use, distribution, and reproduction in any medium, provided you give appropriate credit to the original author(s) and the source, provide a link to the Creative Commons license, and indicate if changes were made.

\section{References}

Papers of particular interest, published recently, have been highlighted as:

- Of importance

•- Of major importance

1. Ehrlich A, Kostecki J, Olkaba H. Trends in dermatology practices and the implications for the workforce. J Am Acad Dermatol. 2017;77(4):746-52. https://doi.org/10.1016/j.jaad.2017.06.030.

2.• Yim KM, Florek AG, Oh DH, McKoy K, Armstrong AW. Teledermatology in the United States: an update in a dynamic era. Telemed E-Health. 2018;24(9):691-7. https://doi.org/10. 1089/tmj.2017.0253. This article provides a comprehensive survey of US teledermatology programs from November 2014 to January 2017, examining annual consultation volume, payment methods, and the number of programs in different practice settings.

3.• Whited JD. Summary of the status of teledermatology research. American Telemedicine Association; 2016. http://www.iagnosis. $\mathrm{com} /$ sites/default/files/2014-summary-status-of-teledermatologyresearch.pdf. Accessed 16 July 2018. A regularly updated and comprehensive assessment of studies in teledermatology comparing results across diagnostic and management reliability, diagnostic and management accuracy, clinical outcomes, quality of life, economic analyses, and satisfaction assessments.

4. Armstrong AW, Wu J, Kovarik CL, Goldyne ME, Oh DH, McKoy $\mathrm{KC}$, et al. State of teledermatology programs in the United States. J Am Acad Dermatol. 2012;67(5):939-44. https://doi.org/10. 1016/j.jaad.2012.02.019.

5. Eccles MP, Mittman BS. Welcome to implementation science. Implement Sci. 2006;1(1):1-3 https://doi.org/10.1186/17485908-1-1.

6. Jackson GL, Krein SL, Alverson DC, Darkins AW, Gunnar W, Harada ND, et al. Defining core issues in utilizing information technology to improve access: evaluation and research agenda. $\mathrm{J}$ Gen Intern Med. 2011;26(S2):623-7. https://doi.org/10.1007/ s11606-011-1789-3.

7. Peters DH, Adam T, Alonge O, Agyepong IA, Tran N. Implementation research: what it is and how to do it. BMJ. 2013;347:f6753-36. https://doi.org/10.1136/bmj.f6753.

8. Bauer MS, Damschroder L, Hagedorn H, Smith J, Kilbourne AM. An introduction to implementation science for the non-specialist. BMC Psychol. 2015;3:32. https://doi.org/10.1186/s40359-0150089-9. A guide to implementation science principles for non-specialists to facilitate the uptake of evidence-based practices to improve health services.

9. Jackson GL, Williams JW. Does PCMH "work"?-the need to use implementation science to make sense of conflicting results. JAMA Intern Med. 2015;175(8):1369-70. https://doi.org/10. 1001/jamainternmed.2015.2067.

10. Klein KJ, Sorra JS. The challenge of innovation implementation. Acad Manag Rev. 1996;21(4):1055-80. https://doi.org/10.5465/ amr.1996.9704071863.

11. Klein KJ, Conn AB, Sorra JS. Implementing computerized technology: an organizational analysis. J Appl Psychol. 2001;86(5): 811-24. https://doi.org/10.1037/0021-9010.86.5.811.

12. Weiner BJ, Lewis MA, Linnan LA. Using organization theory to understand the determinants of effective implementation of worksite health promotion programs. Health Educ Res. 2008;24(2):292-305. https://doi.org/10.1093/her/cyn019.

13. Helfrich CD, Weiner BJ, McKinney MM, Minasian L. Determinants of implementation effectiveness: adapting a 
framework for complex innovations. Med Care Res Rev. 2007;64(3):279-303. https://doi.org/10.1177/ 1077558707299887.

14. Weiner BJ, Haynes-Maslow L, Kahwati LC, Kinsinger LS, Campbell MK. Implementing the MOVE! weight-management program in the Veterans Health Administration, 2007-2010: a qualitative study. Prev Chronic Dis. 2012;9:E16.

15. DiMartino LD, Birken SA, Hanson LC, et al. The influence of formal and informal policies and practices on health care innovation implementation: a mixed-methods analysis. Health Care Manag Rev. 2018;43(3):249-60. https://doi.org/10.1097/HMR. 0000000000000193 .

16. Tabak RG, Khoong EC, Chambers DA, Brownson RC. Bridging research and practice: models for dissemination and implementation research. Am J Prev Med. 2012;43(3):337-50. https://doi.org/ 10.1016/j.amepre.2012.05.024.

17. Glasgow RE, Nelson CC, Strycker LA, King DK. Using RE-AIM metrics to evaluate diabetes self-management support interventions. Am J Prev Med. 2006;30(1):67-73. https://doi.org/10. 1016/j.amepre.2005.08.037.

18. Glasgow RE, McKay HG, Piette JD, Reynolds KD. The RE-AIM framework for evaluating interventions: what can it tell us about approaches to chronic illness management? Patient Educ Couns. 2001;44(2):119-27. https://doi.org/10.1016/S0738-3991(00) 00186-5.

19. Glasgow RE, Vogt TM, Boles SM. Evaluating the public health impact of health promotion interventions: the RE-AIM framework. Am J Public Health. 1999;89(9):1322-7. https://doi.org/ 10.2105/AJPH.89.9.1322.

20. Damschroder LJ, Aron DC, Keith RE, Kirsh SR, Alexander JA, Lowery JC. Fostering implementation of health services research findings into practice: a consolidated framework for advancing implementation science. Implement Sci IS. 2009;4:50. https:// doi.org/10.1186/1748-5908-4-50.

21. Rogers EM. Diffusion of innovations. 4th ed. New York: Free Press; 1995.

22. Gielen AC, McDonald EM, Gary TL, Bone LR. Using the precede-proceed model to apply health behavior theories. In: Glanz K, Rimer BK, Viswanath K, editors. Health behavior and health education theory, research, and practice. 4th ed; 2008. p. 407-29.

23. Graham K, Logan J. Using the Ottawa model of research use to implement a skin care program. J Nurs Care Qual. 2004;19(1):18 24. https://doi.org/10.1097/00001786-200401000-00006.

24. Gaglio B, Shoup JA, Glasgow RE. The RE-AIM framework: a systematic review of use over time. Am J Public Health. 2013;103(6):e38-46. https://doi.org/10.2105/AJPH.2013. 301299 .

25. Tuot DS, Liddy C, Vimalananda VG, Pecina J, Murphy EJ, Keely E, et al. Evaluating diverse electronic consultation programs with a common framework. BMC Health Serv Res. 2018;18(1):814. https://doi.org/10.1186/s12913-018-3626-4.

26. Liddy C, Moroz I, Afkham A, Keely E. Evaluating the implementation of the Champlain BASETM ${ }^{\mathrm{T} C o n s u l t}$ Service in a new region of Ontario, Canada: a cross-sectional study. Healthc Policy. 2013;13(2):79-95. https://doi.org/10.12927/hcpol.2017.25320.

27. Oh DH, Jackson GL, Prentice JC, et al. Implementation of storeand-forward Teledermatology programs to serve rural patients: an evaluation based on the RE-AIM framework: VHA Office of Rural Health Annual Report; 2017.

28. Hue L, Makhloufi S, Sall N'Diaye P, et al. Real-time mobile teledermoscopy for skin cancer screening targeting an agricultural population: an experiment on 289 patients in France. J Eur Acad Dermatol Venereol. 2016;30(1):20-4. https://doi.org/10.1111/jdv. 13404.
29. Moreno-Ramírez D, Ferrándiz L. A 10-year history of teledermatology for skin cancer management. JAMA Dermatol. 2015;151(12):1289. https://doi.org/10.1001/jamadermatol.2015. 3208.

30. Finnane A, Siller G, Mujcic R, Soyer HP. The growth of a skin emergency teledermatology service from 2008 to 2014. Aust J Dermatol. 2016;57(1):14-8. https://doi.org/10.1111/ajd.12411.

31. Tensen E, Van der Heijden JP, Jaspers MWM, Witkamp L. Two decades of teledermatology: current status and integration in national healthcare systems. Curr Dermatol Rep. 2016;5(2):96-104. https://doi.org/10.1007/s13671-016-0136-7.

32. Ismail A, Stoff BK, McMichael JR. Store-and-forward teledermatology service for primary care providers in Afghanistan. Int J Dermatol. 2018;57(11):e145-7. https://doi. org/10.1111/ijd.14165.

33. Lipoff JB, Cobos G, Kaddu S, Kovarik CL. The Africa teledermatology project: a retrospective case review of 1229 consultations from sub-Saharan Africa. J Am Acad Dermatol. 2015;72(6):1084-5. https://doi.org/10.1016/j.jaad.2015.02.1119.

34. Faye O, Bagayoko C, Dicko A, Cissé L, Berthé S, Traoré B, et al. A teledermatology pilot programme for the management of skin diseases in primary health care centres: experiences from a resource-limited country (Mali, West Africa). Trop Med Infect Dis. 2018;3(3):88. https://doi.org/10.3390/tropicalmed3030088.

35. Williams V, Kovarik C. WhatsApp: an innovative tool for dermatology care in limited resource settings. Telemed J EHealth. 2018;24(6):464-8.

36. Mazzuoccolo LD, Esposito MN, Luna PC, Seiref S, Dominguez M, WhatsApp ECM. A real-time tool to reduce the knowledge gap and share the best clinical practices in psoriasis. Telemed EHealth. 2018;0(0). https://doi.org/10.1089/tmj.2018.0059.

37. Saleh N, Abdel Hay R, Hegazy R, Hussein M, Gomaa D. Can teledermatology be a useful diagnostic tool in dermatology practice in remote areas? An Egyptian experience with 600 patients. J Telemed Telecare. 2017;23(2):233-8. https://doi.org/10.1177/ 1357633 X16633944.

38. Von Wangenheim A, Nunes DH. Creating a web infrastructure for the support of clinical protocols and clinical management: an example in teledermatology. Telemed E-Health. 2018;25(10). https://doi.org/10.1089/tmj.2018.0197.

39. Landow SM, Oh DH, Weinstock MA. Teledermatology within the veterans health administration, 2002-2014. Telemed E-Health. 2015;21(10):769-73. https://doi.org/10.1089/tmj.2014.0225. This article provides a description of the expansion of the Veterans Health Administration's teledermatology program, using routinely collected data to examine time to consult completion, urban rural differences and both store and forward and live video use.

40. Raugi GJ, Nelson W, Miethke M, Boyd M, Markham C, Dougall $\mathrm{B}$, et al. Teledermatology implementation in a VHA secondary treatment facility improves access to face-to-face care. Telemed E-Health. 2016;22(1):12-7. https://doi.org/10.1089/tmj.2015. 0036.

41. Uscher-Pines L, Malsberger R, Burgette L, Mulcahy A, Mehrotra A. Effect of teledermatology on access to dermatology care among medicaid enrollees. JAMA Dermatol. 2016;152(8):905-11.

42. Leavitt ER, Kessler S, Pun S, Gill T, Escobedo LA, Cockburn M, et al. Teledermatology as a tool to improve access to care for medically underserved populations: a retrospective descriptive study. J Am Acad Dermatol. 2016;75(6):1259-61.

43. Nelson CA, Takeshita J, Wanat KA, Bream KDW, Holmes JH, Koenig HC, et al. Impact of store-and-forward (SAF) teledermatology on outpatient dermatologic care: a prospective study in an underserved urban primary care setting. J Am Acad Dermatol. 2016;74(3):484-490.e1. https://doi.org/10.1016/j.jaad. 2015.09.058 
44. Eber EL, Janda M, Arzberger E, Hofmann-Wellenhof R. Survey on the status of teledermatology in Austria. J Ger Soc Dermatol. 2019;17(1):25-31.

45. Rajda J, Fernandes J, Fox K, Paz H. Impact of direct to consumer store-and-forward teledermatology on access to care, satisfaction, utilization, and costs in a commercial health plan population. Telemed E-Health. 2018;24(2):166-9. https://doi.org/10.1089/ tmj.2017.0078.

46. Marcell R, Locatis C, Burgess G, Maisiak R, Liu W-L, Ackerman M. Patient and provider satisfaction with teledermatology. Telemed E-Health. 2017;23(8):684-90.

47. Altieri L, Hu J, Nguyen A, Cockburn M, Chiu M, Cotliar J, et al. Interobserver reliability of teledermatology across all Fitzpatrick skin types. J Telemed Telecare. 2017;23(1):68-73. https://doi.org/ 10.1177/1357633X15621226.

48. Wang M, Gendreau JL, Gemelas J, Capulong D, Lau C, MataDiaz S, et al. Diagnosis and management of malignant melanoma in store-and-forward teledermatology. Telemed E-Health. 2017;23(11):877-80. https://doi.org/10.1089/tmj.2017.0009.

49. Markun S, Scherz N, Rosemann T, Tandjung R, Braun RP. Mobile teledermatology for skin cancer screening: a diagnostic accuracy study. Medicine (Baltimore). 2017;96(10):e6278. https://doi.org/ 10.1097/MD.0000000000006278.

50. Nami N, Massone C, Rubegni P, Cevenini G, Fimiani M, Hofmann-Wellenhof R. Concordance and time estimation of store-and-forward mobile teledermatology compared to classical face-to-face consultation. Acta Derm Venereol. 2015;95(1):35-9. https://doi.org/10.2340/00015555-1876.

51. Naka F, Lu J, Porto A. Impact of dermatology eConsults on access to care and skin cancer screening in underserved populations: a model for teledermatology services in community health centers. J Am Acad Dermatol. 2018;78(2):293-302. This cross-sectional study explores the accuracy of store and forward teledermatology to triage patients for Mohs surgery directly, finding benefits for lesions with high pre-test probability of malignancy.

52. Bezalel S, Fabri P, Park HS. Implementation of store-and-forward teledermatology and its associated effect on patient access in a Veterans Affairs Dermatology clinic. JAMA Dermatol. 2015;151(5):556. https://doi.org/10.1001/jamadermatol.2014. 5272 .

53. Cotes ME, Albers LN, Sargen M, Chen SC. Diagnostic accuracy of teledermatology for nonmelanoma skin cancer: can patients be referred directly for surgical management? J Am Acad Dermatol. 2017. https://doi.org/10.1016/j.jaad.2017.09.029.

54. Mohan GC, Molina GE, Stavert R. Store and forward teledermatology improves dermatology knowledge among referring primary care providers: a survey-based cohort study. J Am Acad Dermatol. 2018;79(5):960-1. This pilot study found teledermatology increased both the dermatologic knowledge of primary care providers and their confidence in providing dermatologic care. This difference increased with greater exposure to teledermatology consultation requests.

55. Whited JD. Quality of life: a research gap in teledermatology. Int J Dermatol. 2015;54(10):1124-8. https://doi.org/10.1111/ijd. 12909.

56. Byamba K, Syed-Abdul S, García-Romero M, Huang CW, Nergyi S, Nyamdorj A, et al. Mobile teledermatology for a prompter and more efficient dermatological care in rural Mongolia. Br J Dermatol. 2015;173(1):265-7. https://doi.org/10.1111/bjd.13607.

57. Livingstone J, Solomon J. An assessment of the cost-effectiveness, safety of referral and patient satisfaction of a general practice teledermatology service. Lond J Prim Care. 2015;7(2):31-5.

58. Yang X, Barbieri JS, Kovarik CL. Cost analysis of a store and forward teledermatology consult system in Philadelphia. J Am Acad Dermatol. 2018. https://doi.org/10.1016/j.jaad.2018.09.036.
59. Datta SK, Warshaw EM, Edison KE, Kapur K, Thottapurathu L, Moritz TE, et al. Cost and utility analysis of a store-and-forward teledermatology referral system: a randomized clinical trial. JAMA Dermatol. 2015;151(12):1323-9. https://doi.org/10.1001/ jamadermatol.2015.2362. This randomized clinical trial provides a comprehensive assessment of the costs of a storeand-forward teledermatology referral process compared with a conventional referral process during a 9-month period. They found comparable costs from the perspective of the VA, lower cost from a societal perspective, and in an examination of the time trade-off utility, they found no difference.

60. O'Connor D, Jew O, Perman M, Castelo-Soccio L, Winston F, McMahon P. Diagnostic accuracy of pediatric teledermatology using parent-submitted photographs: a randomized clinical trial. JAMA Dermatol. 2017;153(12):1243-8.

61. Ngoo A, Finnane A, McMeniman E, Tan J, Janda M, Soyer H. Efficacy of smartphone applications in high-risk pigmented lesions. Aust J Dermatol. 2018;59(3):e175-82. https://doi.org/10. 1111/ajd.12599.

62. Resneck JS, Abrouk M, Steuer M, et al. Choice, transparency, coordination, and quality among direct-to-consumer telemedicine websites and apps treating skin disease. JAMA Dermatol. 2016;152(7):768. https://doi.org/10.1001/jamadermatol.2016. 1774. Authors found current direct-to-consumer telemedicine websites and smartphone apps lacked transparency and choice, and risked low quality care specifically reagrding diagnoses, treatment, and care coordination of skin disease.

63. Armstrong AW, Chambers CJ, Maverakis E, et al. Effectiveness of online vs in-person care for adults with psoriasis a randomized clinical trial. JAMA Netw Open. 2018;1(6):1-15.

64. Chamberlain P, Brown CH, Saldana L. Observational measure of implementation progress in community based settings: the stages of implementation completion (SIC). Implement Sci. 2011;6(116). https://doi.org/10.1186/1748-5908-6-116.

65. Saldana L. The stages of implementation completion for evidencebased practice: protocol for a mixed methods study. Implement Sci. 2014;9(43). https://doi.org/10.1186/1748-5908-9-43.

66. Walters LEM, Scott RE, Mars MA. Teledermatology scale-up framework and roadmap for sustainable scaling: evidence-based development. J Med Internet Res. 2018;20(6):e224. https://doi. org/10.2196/jmir.9940.

67. Bobbs M, Bayer M, Frazer T, Humphrey S, Wilson B, Olasz E, et al. Building a global teledermatology collaboration. Int $\mathrm{J}$ Dermatol. 2016;55:446-9. https://doi.org/10.1111/ijd.13223. This article examines the implemenation process of an international partnered teledermatology program covering many aspects included in the RE-AIM framework.

68. Williams V, Kovarik C. Long-range diagnosis of and support for skin conditions in field settings. Trop Med Infect Dis. 2018;3(3): 84. https://doi.org/10.3390/tropicalmed3030084.

69. Madu PN, Chang AY, Kayembe MK, Kovarik CL. Teledermatology as a means to provide multispecialty care: a case of global specialty collaboration. Pediatr Dermatol. 2017;34(2):e89-92. https://doi.org/10.1111/pde.13079.

70. McKoy K, Antoniotti N, Armstrong AW, et al. Telemed practice guidelines for teledermatology. J E Health. 2016;22(12):981-90.

71. Position statement on teledermatology. https://www.aad.org/ Forms/Policies/Uploads/PS/PS-Teledermatology.pdf. Accessed $15^{\text {th }}$ August 2018

72. Lee JJ, English JC. Teledermatology: a review and update. Am J Clin Dermatol. 2018;19(2):253-60. https://doi.org/10.1007/ s40257-017-0317-6.

73. Department of Veterans Affairs. Authority of health care providers to practice telehealth. Fed Regist. 2018;83(92):21897-907.

74. VA MISSION Act of 2018; 2018. https://www.congress.gov/bill/ 115th-congress/senate-bill/2372/text. Accessed 14 January 2019 
75. Davis FD. Perceived usefulness, perceived ease of use, and user acceptance of information technology. MIS Q. 1989;13(3):319. https://doi.org/10.2307/249008.

76. Orruño E, Gagnon MP, Asua J, Ben AA. Evaluation of teledermatology adoption by health-care professionals using a modified technology acceptance model. J Telemed Telecare. 2011;17(6):303-7.

77. Christiansen EK, Henriksen E, Jensen LK, et al. D3.2 Towards a personalised blueprint - for doers, by doers: consolidated version. http://www.telemedicine-momentum.eu/wp-content/uploads/ 2014/12/D3.2_v13_Momentum_ConsolidatedBlueprint.pdf. Accessed 18 July 2018.

78. Weiner BJ. A theory of organizational readiness for change. Implement Sci. 2009;4(1). https://doi.org/10.1186/1748-5908-4-67.

79. Ariens LF, Schussler-Raymakers FM, Frima C, et al. Barriers and facilitators to eHealth use in daily practice: perspectives of patients and professionals in dermatology. J Med Internet Res. 2017;19(9): e300. https://doi.org/10.2196/jmir.7512.

80. Gendreau JL, Gemelas J, Wang M, Capulong D, Lau C, Bratten $\mathrm{DM}$, et al. Unimaged melanomas in store-and-forward teledermatology. Telemed E-Health. 2017;23(6):517-20. https:// doi.org/10.1089/tmj.2016.0170.

81. Pecina JL, Frank JM, North F. A retrospective study on how primary care providers manage specialists' recommendations after an e-consultation. SAGE Open Med. 2016;4:205031211668212. https://doi.org/10.1177/2050312116682127.

82. Swinkels ICS, Huygens MWJ, Schoenmakers TM, Oude Nijeweme-D'Hollosy W, van Velsen L, Vermeulen J, et al. Lessons learned from a living lab on the broad adoption of eHealth in primary health care. J Med Internet Res. 2018;20(3): e83. https://doi.org/10.2196/jmir.9110.

83. Cheeley J, Chen S, Swerlick R. Consultative teledermatology in the emergency department and inpatient wards: a survey of potential referring providers. J Am Acad Dermatol. 2018;79(2):384-6. https://doi.org/10.1016/j.jaad.2018.01.033.

84. Carter Z, Goldman S, Anderson K, et al. Creation of an internal teledermatology store-and-forward system in an existing electronic health record: a pilot study in a safety-net public health and hospital system. JAMA Dermatol. 2017;153(7):644-50.

85. Mehrtens S, Halpern S. Changing use and attitudes towards teledermatology in the U.K. over 10 years: results of the 2016 National Survey. Br J Dermatol. 2018;178(1):286-8.

86. Abbott LM, Magnusson RS, Gibbs E, Smith SD. Smartphone use in dermatology for clinical photography and consultation: current practice and the law. Aust J Dermatol. 2018;59(2):101-7.

87. Fogel AL, Sarin KY. A survey of direct-to-consumer teledermatology services available to US patients: explosive growth, opportunities and controversy. J Telemed Telecare. 2017;23(1):19-25. https://doi.org/10.1177/1357633X15624044.

88. Rosen AR, Littman-Quinn R, Kovarik CL, Lipoff JB. Landscape of business models in teledermatology. Cutis. 2016;97(4):302-4.
89. Coates SJ, Kyedar J, Granstein RD. Teledermatology: from historical perspective to emerging techniques of the modern era. J Am Acad Dermatol. 2015;72(4):563-74.

90. Kochmann M, Locatis C. Direct to consumer mobile teledermatology apps: an exploratory study. Telemed E-Health 2016;22(8):689-93. https://doi.org/10.1089/tmj.2015.0189.

91. Kim G, Afanasiey O, O’Dell C, Sharp C, Ko J. Implementation and evaluation of Stanford Health Care store-and-forward teledermatology consultation workflow built within an existing electronic health record system. J Telemed Telecare. 2018;0(0): $1-7$.

92. Martin I, Aphivantrakul PP, Chen K-H, Chen SC. Adherence to teledermatology recommendations by primary health care professionals: strategies for improving follow-up on teledermatology recommendations. JAMA Dermatol. 2015;151(10):1130-2.

93. Campagna M, Naka F, Lu J. Teledermatology: an updated overview of clinical applications and reimbursement policies. Int $\mathrm{J}$ Womens Dermatol. 2017;3(3):176-9. https://doi.org/10.1016/j. ijwd.2017.04.002.

94. Byrom L, Lucas L, Sheedy V, et al. Tele-Derm national: a decade of teledermatology in rural and remote Australia. Aust J Rural Health. 2016;25:193-9.

95. Greisman L, Nguyen TM, Mann RE, et al. Feasibility and cost of a medical student proxy-based mobile teledermatology consult service with Kisoro, Uganda, and Lake Atitlan, Gautemala. Int J Dermatol. 2015;54(6):685-92.

96. Sáenz JP, Novoa MP, Correal D, Eapen BR. On using a mobile application to support teledermatology: a case study in an underprivileged area in Colombia. Int J Telemed Appl. 2018;2018:1-8. https://doi.org/10.1155/2018/1496941.

97. Boyers L, Schultz A, Baceviciene R, et al. Teledermatology as an educational tool for teaching dermatology to residents and medical students. Telemed J EHealth. 2015;21(4):312-4.

98. Yeung H, Sargen MR, Luk KM, Berry EG, Gurnee EA, Heuring $\mathrm{E}$, et al. Teledermatology and teledermatopathology as educational tools for international dermatology: a virtual grand rounds pilot curriculum. Int J Dermatol. 2018;57(11):1358-62. https://doi.org/ 10.1111/ijd.14014.

99. Wanat KA, Newman S, Finney KM, Kovarik CL, Lee I. Teledermatology education: current use of teledermatology in US residency programs. J Grad Med Educ. 2016;8(2):286-7. https://doi.org/10.4300/JGME-D-16-00041.1.

100. Mancini JA, Marek LI. Sustaining community-based programs for families: conceptualization and measurement. Fam Relat. 2004;53(4):339-47.

Publisher's Note Springer Nature remains neutral with regard to jurisdictional claims in published maps and institutional affiliations. 